\title{
BMJ Open Relationship between physician financial incentives and clinical pathway compliance: a cross-sectional study of 18 public hospitals in China
}

\author{
Jie Bai, ${ }^{1,2}$ Kate Bundorf, ${ }^{3}$ Fei Bai, ${ }^{4}$ Huiqin Tang, ${ }^{5}$ Di Xue ${ }^{\bullet 1,2}$
}

To cite: Bai J, Bundorf K, Bai F, et al. Relationship between physician financial incentives and clinical pathway compliance: a crosssectional study of 18 public hospitals in China. BMJ Open 2019;9:e027540. doi:10.1136/ bmjopen-2018-027540

- Prepublication history and additional material for this paper are available online. To view these files, please visit the journal online (http://dx.doi. org/10.1136/bmjopen-2018027540).

Received 27 October 2018 Revised 17 March 2019 Accepted 29 April 2019

Check for updates

(c) Author(s) (or their employer(s)) 2019. Re-use permitted under CC BY-NC. No commercial re-use. See rights and permissions. Published by BMJ.

${ }^{1}$ Hospital Management, School of Public Health, Fudan University, Shanghai, China ${ }^{2} \mathrm{CHC}$ Key Lab of Health Technology Assessment (Fudan University), Shanghai, China ${ }^{3}$ Health Research and Policy, School of Medicine, Stanford University, Stanford, California, USA

${ }^{4}$ Technological Guidance, National Center for Medical Service Administration, Beijing, China

${ }^{5}$ Medical Administration, Health Commission of Hubei Province, Wuhan, China

Correspondence to

Professor Di Xue;

xuedi@shmu.edu.cn

\section{ABSTRACT}

Objectives Many strategies have been either used or recommended to promote physician compliance with clinical practice guidelines and clinical pathways (CPs). This study examines the relationship between hospitals' use of financial incentives to encourage physician compliance with CPs and physician adherence to CPs. Design A retrospectively cross-sectional study of the relationship between the extent to which patient care was consistent with CPs and hospital's use of financial incentives to influence CP compliance.

Setting Eighteen public hospitals in three provinces in China.

Participants Stratified sample of 2521 patients discharged between 3 January 2013 and 31 December 2014.

Primary outcome measures The proportion of key performance indicators (KPIs) met for patients with (1) community-acquired pneumonia (pneumonia), (2) acute myocardial infarction (AMI), (3) acute left ventricular failure (heart failure), (4) planned caesarean section (C-section) and (5) gallstones associated with acute cholecystitis and associated cholecystectomy (cholecystectomy).

Results The average implementation rate of CPs for five conditions (pneumonia, AMI, heart failure, C-section and cholecystectomy) based on 2521 cases in 18 surveyed hospitals was $57 \%$ (ranging from $44 \%$ to $67 \%$ ), and the overall average compliance rate for the KPIs for the five conditions was $69.48 \%$ (ranging from $65.07 \%$ to $77.36 \%$ ). Implementation of CPs was associated with greater compliance within hospitals only when hospitals adopted financial incentives directed at physicians to promote compliance.

Conclusion CPs are viewed as important strategies to improve medical care in China, but they have not been widely implemented or adhered to in Chinese public hospitals. In addition to supportive resources, education/ training and better administration in general, hospitals should provide financial incentives to encourage physicians to adhere to CPs.

\section{INTRODUCTION}

Policymakers in China have promoted the use of clinical practice guidelines (CPGs) and clinical pathways (CPs) as a key strategy to improve the effectiveness and efficiency

\section{Strengths and limitations of this study}

- The study involves the five selected conditions which cover medical care in internal medicine, surgery and obstetrics.

- This study has a large sample of 2521 patients from 18 public general hospitals in three provinces representing high, middle and low socioeconomic status levels in the eastern, central and western regions of China.

- It is possible that the medical care provided to patients is more compliant with clinical pathways than our results suggest as we considered the physician non-compliant if information was not available in the medical record for a particular indicator.

- While we analysed five different conditions, the results may not be generalisable to all health conditions.

of care delivery since 2009. ${ }^{1}$ The National Health Commission (NHC, previously called National Health and Family Planning Commission) of China facilitated the implementation of CPGs and CPs by issuing 1010 national CPs by the end of 2016, and announcing a hospital payment reform more strongly linking payment to CPs through the use of a system similar to diagnosis-related groups in which hospitals receive a prospective payment for a single disease, that is, based on its corresponding CP. ${ }^{2}$ In this paper, we examine the use of CPs in hospitals in three regions in China, focusing on the relationship between how hospitals implemented CPs and the extent to which patients received CP-compliant care.

\section{CPs and CPGs}

CPs and CPGs, together with clinical decision rules, are referred to as evidence-based clinical algorithms (EBCAs). ${ }^{3}$ CPs identify the specific steps and key aspects of medical treatment to support the translation of CPGs into local practice. ${ }^{45}$ In China, the NHC issued 
national CPs to help hospitals translate national CPGs into local practice, although hospitals may customise these CPs for their patients. ${ }^{1}$ In 2015, 94.4\% of the public hospitals in China implemented CPs and among which, an average of 45 CPs were implemented. ${ }^{6}$ However, the extent to which physicians in Chinese hospitals follow these CPGs and CPs and the factors that affect their compliance remain unclear.

\section{Compliance with CPs and CPGs}

CPGs and CPs will only affect medical care if physicians follow them. ${ }^{78}$ While many strategies have been used or recommended to promote physician compliance with CPGs and CPs, ${ }^{9-13}$ compliance rates have generally been low and highly variant, ranging from $12 \%$ for anaemia targets in patients with stable chronic haemodialysis ${ }^{14}$ to $15 \%$ in patients with allergic rhinitis, ${ }^{15} 27 \%$ for adequate drug regimens in patients with newly diagnosed smear-positive pulmonary tuberculosis, ${ }^{16} 46 \%$ in patients with severe traumatic brain injury, ${ }^{17} 52 \%$ in patients with hypertension, ${ }^{18} 1944 \%$ and $62 \%$ for appropriate use of antibiotic prophylaxis at preintervention and follow-up to prevent paediatric surgical site infection, respectively, ${ }^{9}$ and $62 \%$ for the prescribing of antibiotics in acute infections at Namibia's national referral hospital. $^{20}$

\section{Factors that influence the implementation of CPs and CPGs}

Social, organisational, cognitive and motivational factors have been suggested as four broad themes for analysing the factors affecting knowledge transfer of EBCAs, ${ }^{3}$ and many papers have discussed the effects of particular factors on the implementation of CPGs or CPs. ${ }^{3} 18$ 21-26 Some papers emphasise motivational factors, including competing priorities, physicians' innate resistance to behaviour change, self-motivation, altruism, individual drive for excellence, pressure from peers, fear of negative consequences, fear of patient disputes and litigation, and reward schemes for individual behaviour aligned with the implementation of CPs. ${ }^{327}$

Motivational benefits usually focus on CPs role in providing physicians with clear clinical steps, a feeling of safety in providing quality inpatient care, the ability to stay abreast of knowledge and to improve efficiency. ${ }^{28}$ Financial incentives may also motivate behaviour, and the absence of financial incentives is believed to be a barrier to implementation. ${ }^{29}$ Findings from studies of the effects of organisational reward schemes on physicians' implementation of CPGs or CPs in UK and Europe vary, ranging from uncertain or minor effects to an over $60 \%$ increase in process compliance. ${ }^{30-32}$ Theses type of studies in China are limited but needed. ${ }^{333}$

The aims of our study are to understand the extent to which physicians adhere to national CPs in Chinese hospitals and to analyse the main factors that influenced their compliance, particularly financial incentives.

\section{METHODS}

We analysed the implementation of CPs using data from 18 hospitals in three provinces in China. We combined information from hospital surveys about the organisation's implementation of CPs with data abstracted from the medical charts of randomly selected patients admitted with one of five medical conditions to analyse the relationship between CP implementation and care delivery.

\section{Study sample}

The study was conducted in Shanghai, Hubei Province and Gansu Province, representing high, middle and low levels of socioeconomic status as well as the eastern, central and western regions of China. In Hubei Province and Gansu Province, three areas (cities or autonomous prefectures) were selected to represent high, middle and low socioeconomic status within each province. In each area of Hubei Province and Gansu Province, one tertiary and one secondary general public hospital was selected. Because tertiary general public hospitals in Shanghai are not evenly distributed across districts, three tertiary general public hospitals in Shanghai were selected to represent tertiary hospitals owned by a university, by the Shanghai government and by the district government. In Shanghai, three secondary general public hospitals were selected from three districts to represent hospitals in urban, suburban and rural areas.

\section{Data sources}

Hospital survey

Eighteen hospitals (including nine tertiary and nine secondary hospitals) were surveyed using the paperbased questionnaires designed specifically for the study to collect data about the hospital location, the level of care provided by the hospital, whether and when the hospital had implemented CPs for five conditions, and what types of financial incentive schemes the hospital had implemented to influence physicians' behaviour with respect to CPs. Questions on CP implementation focused on the following five conditions: (1) community-acquired pneumonia (pneumonia), (2) acute myocardial infarction (AMI), (3) acute left ventricular failure (heart failure), (4) planned caesarean section (C-section) and (5) gallstones associated with acute cholecystitis and associated cholecystectomy (cholecystectomy). These five conditions are common in general hospitals and cover medical care in internal medicine, surgery and obstetrics. In addition, each condition has a national $\mathrm{CP}$ as well as a CP or CPG, that is, used in at least one developed country. The hospital questionnaires were completed by the managers in the medical affairs offices or in hospital general management offices.

\section{Chart review}

We collected information on treatment patterns for each of the five conditions by reviewing patient charts. We identified all patients admitted to each hospital in 2014 for each of the five conditions based on international 
classification of diseases codes (ICD-10 or ICD-9). To ensure that the sample was evenly distributed throughout the year, we selected 2 3 cases for each condition in each month so that 30 cases for each condition were sampled in each hospital. If a hospital admitted $<30$ patients for a particular condition in 2014, then all medical records from 2014 and some medical records from late 2013 or even all of 2013 were extracted so that 30 records could be extracted for each condition in each hospital.

For most hospitals, hospital information systems were used to identify cases and to collect inpatient information (such as age, gender and medical insurance). However, some hospitals in rural areas did not have electronic health information systems, and, as a result, the cases were identified and inpatient information was collected manually.

\section{Development of key performance indicators}

We developed an audit chart with key performance indicators (KPIs) corresponding to the CP for each of the five conditions. Auditors extracted information from the medical records corresponding to each item in the audit chart for each patient. To ensure the quality and consistency of the chart audits, we trained 18 auditors on the meaning of each item on the checklist and how to judge whether the KPIs were met. In addition, 10 medical experts were invited to review medical records for the five conditions in two hospitals. The auditors reviewed the same medical records to analyse the consistency of medical review between experts and auditors. One inspector was also assigned to check $10 \%$ of the reviewed charts for each condition in each hospital. The consistency rates between auditors and experts and between auditors and inspectors were $90.82 \%$ and $90.88 \%$, respectively.

We identified the most important elements of the CP published by NHC for each condition and the corresponding KPIs from the chart audit, such as timely tests and examinations, adequate use of antibiotics and other medications, reasonable treatment and appropriate length of stay, associated with that element. We selected 13 KPIs for pneumonia, 12 for AMI, 12 for heart failure, 11 for C-section and 15 for cholecystectomy for the chart reviews. $^{34}$

\section{Measures of hospital financial incentives}

The hospital-level survey collected information on whether the hospital had adopted a CP for each of the five conditions, and among those adopting the CP for a particular condition, whether the hospitals implemented financial incentives targeted at physicians to encourage compliance with the CP. The survey respondent could indicate that they provided bonuses for physicians in the clinical department as a whole or bonuses for individual physicians based on CP performance. Thus, for each hospital, we created an indicator of whether the hospital adopted a CP for each condition and whether the implementation of the CP was accompanied by the use of financial incentives.

\section{Data analysis}

We calculated the proportion of KPIs that was met for each patient based on the patient's condition. We defined care as compliant for an indicator only if the care provided was consistent with the CP and was recorded in the medical record or if the medical record included a reasonable explanation for not complying. For each KPI, the auditors judged whether the patient received compliant or non-compliant care and then coded it with a ' 1 ' or ' 0 ', respectively. We then calculated the proportion of indicators met for each patient.

This patient-level measure was used to calculate the average proportion of KPIs that was met across all patients with a given condition in single hospital or in hospitals of a common specific type (average compliance rate). We compared the average compliance rates of the five conditions by hospital level (tertiary vs secondary), by whether the hospital had adopted a CP for that condition, and, among hospitals adopting CPs, by whether the implementation of CPs was accompanied by the use of financial incentives targeted to physicians. We calculated the statistical significance of the differences using t tests.

We estimated a multivariate linear regression model to test whether differences across hospitals in compliance rates based on $\mathrm{CP}$ adoption and the use of financial incentives were robust to including controls for patient and hospital characteristics. We estimated the model using patient-level data, pooled across patients with each of the five conditions, with the patient-level compliance rate (the portion of KPIs for the patient's condition that were met) as the dependent variable. Control variables included patient characteristics (age, sex, insurance status and indicator of health condition) and hospital fixed effects (created dummy variables representing the different hospitals). The hospital fixed effects control for all characteristics of the hospitals that are fixed across patient types including those that are observable, such as location and hospital level, and those that are less easily measured, such as average quality of care. The independent variables of interest were indicators of whether the hospital had implemented a CP for the patient's condition and whether the implementation of the $\mathrm{CP}$ was accompanied by the use of financial incentives directed at physicians. We were able to include these variables in the model with the hospital fixed effects since the hospitals varied based on for which conditions they had implemented CPs and, among those conditions for which they had implemented CPs, which were associated with financial incentives. Thus, our estimates of the effects of the use of CPs are based on within-hospital differences in compliance rates across conditions associated with whether the hospital adopted a CP for the condition and whether the $\mathrm{CP}$ was implemented with physician financial incentives.

\section{Patient and public involvement}

Patients were not involved in the design or conduct of the study. 


\section{Ethics approval}

In addition, the study collected data from hospital survey and inpatient chart review without patients' sensitive personal information. Therefore, the study got the approval for informed consent exempt from the institutional review board.

\section{RESULTS}

\section{General information}

The study was based on 2521 cases from 18 hospitals, including 534 cases of pneumonia, 487 cases of AMI, 426 cases of heart failure, 538 cases of C-sections and 536 cholecystectomies. Among all cases, $34.71 \%, 33.76 \%$ and $31.53 \%$ were from Shanghai, Hubei Province and Gansu Province, respectively; $52.12 \%$ were from tertiary hospitals, $40.00 \%$ were male, $58.18 \%$ were aged 50 years or older and $25.37 \%$ had no medical insurance (see online supplementary appendix table 1 ).

The hospitals varied in which of the five conditions they choose for CP implementation. Twelve out of 18 hospitals (67\%) implemented a pneumonia CP, 11 (61\%) implemented one for AMI, 8 (44\%) implemented one for heart failure, $11(61 \%)$ implemented one for C-section and 9 $(50 \%)$ implemented one for cholecystectomy. In addition, of the 16 hospitals that implemented at least one CP, $6(37.50 \%)$ had financial incentive schemes to encourage physician compliance with CPs (see online supplementary appendix table 2).

\section{Compliance rates}

The overall average compliance rate for the KPIs across the five conditions was $69.48 \%$. The average compliance rates for pneumonia, AMI, heart failure, C-section and cholecystectomy were $65.07 \%, 68.87 \%, 68.04 \%$, $77.36 \%$ and $67.65 \%$, respectively (table 1); the compliance rates for the KPIs for the five conditions ranged from $0.75 \%$ to $97.57 \%, 39.63 \%$ to $97.95 \%, 32.86 \%$ to $98.12 \%$, $28.44 \%$ to $99.81 \%$ and $5.78 \%$ to $100.00 \%$, respectively.

Specifically, the compliance rates of 'Tests and examinations within 3 days of admission' and 'Severe patients (defined as oxygen saturation $<92 \%$ ) received blood gas analysis' for pneumonia were $0.75 \%$ and $90.82 \%$, respectively; the compliance rates of 'percutaneous coronary intervention (PCI) within 90 min of admission', 'Thrombolytic therapy within 30 min of admission' and 'Use of

\begin{tabular}{|c|c|c|c|c|c|c|c|c|}
\hline Conditions & No of cases & Mean & SD & Median & Max & Min & t Value & $P$ value \\
\hline \multicolumn{9}{|l|}{ Pneumonia } \\
\hline Tertiary & 270 & 66.21 & 12.71 & 69.23 & 92.31 & 23.08 & 3.12 & 0.0019 \\
\hline Secondary & 264 & 63.90 & 14.82 & 61.54 & 100.00 & 23.08 & - & - \\
\hline Total & 534 & 65.07 & 13.83 & 61.54 & 100.00 & 23.08 & - & - \\
\hline \multicolumn{9}{|l|}{ AMI } \\
\hline Tertiary & 260 & 71.09 & 15.16 & 75.00 & 100.00 & 16.67 & 3.49 & 0.0005 \\
\hline Secondary & 227 & 66.34 & 14.82 & 66.67 & 100.00 & 25.00 & - & - \\
\hline Total & 487 & 68.87 & 15.17 & 66.67 & 100.00 & 16.67 & - & - \\
\hline \multicolumn{9}{|l|}{ Heart failure } \\
\hline Tertiary & 245 & 67.45 & 13.36 & 0.67 & 1.00 & 0.33 & -1.09 & 0.2779 \\
\hline Secondary & 181 & 68.83 & 12.43 & 0.67 & 1.00 & 0.33 & - & - \\
\hline Total & 426 & 68.04 & 12.98 & 66.67 & 100.00 & 33.33 & - & - \\
\hline \multicolumn{9}{|l|}{ C-section } \\
\hline Tertiary & 271 & 78.23 & 12.11 & 81.82 & 100.00 & 36.36 & 1.76 & 0.0798 \\
\hline Secondary & 267 & 76.47 & 11.07 & 81.82 & 100.00 & 18.18 & - & - \\
\hline Total & 538 & 77.36 & 11.63 & 81.82 & 100.00 & 18.18 & - & - \\
\hline \multicolumn{9}{|c|}{ Cholecystectomy } \\
\hline Tertiary & 268 & 71.42 & 11.63 & 73.33 & 93.33 & 40.00 & 7.77 & $<0.0001$ \\
\hline Secondary & 268 & 63.88 & 10.82 & 66.67 & 86.67 & 40.00 & - & - \\
\hline Total & 536 & 67.65 & 11.84 & 66.67 & 93.33 & 40.00 & - & - \\
\hline \multicolumn{9}{|c|}{ Five conditions } \\
\hline Tertiary & 1314 & 70.95 & 13.68 & 72.73 & 100.00 & 16.67 & 5.62 & $<0.0001$ \\
\hline Secondary & 1207 & 67.87 & 13.75 & 66.67 & 100.00 & 18.18 & - & - \\
\hline Total & 2521 & 69.48 & 13.80 & 69.23 & 100.00 & 16.67 & - & - \\
\hline
\end{tabular}

AMI, acute myocardial infarction. 
Table 2 Comparison of the average compliance rates of hospitals with and without CP implementation

\begin{tabular}{|c|c|c|c|c|c|c|c|c|c|c|c|}
\hline \multirow[b]{2}{*}{ Conditions } & \multicolumn{3}{|c|}{ Hospitals adopting CPs } & \multicolumn{3}{|c|}{ Hospitals not adopting CPs } & \multicolumn{3}{|l|}{ Total } & \multirow[b]{2}{*}{ t Value } & \multirow[b]{2}{*}{$P$ value } \\
\hline & $\begin{array}{l}\text { No of } \\
\text { hospitals }\end{array}$ & $\begin{array}{l}\text { No of } \\
\text { cases }\end{array}$ & $\begin{array}{l}\text { Compliance } \\
\text { rate (\%) }\end{array}$ & $\begin{array}{l}\text { No of } \\
\text { hospitals }\end{array}$ & $\begin{array}{l}\text { No of } \\
\text { cases }\end{array}$ & $\begin{array}{l}\text { Compliance } \\
\text { rate }(\%)\end{array}$ & $\begin{array}{l}\text { No of } \\
\text { hospitals }\end{array}$ & $\begin{array}{l}\text { No of } \\
\text { cases }\end{array}$ & $\begin{array}{l}\text { Compliance } \\
\text { rate (\%) }\end{array}$ & & \\
\hline AMI & 11 & 316 & 69.09 & 7 & 171 & 68.47 & 18 & 487 & 68.87 & 0.43 & 0.6658 \\
\hline Heart failure & 8 & 209 & 68.94 & 10 & 217 & 67.17 & 18 & 426 & 68.04 & 1.41 & 0.1587 \\
\hline C-section & 11 & 329 & 77.34 & 7 & 209 & 77.38 & 18 & 538 & 77.36 & -0.04 & 0.9684 \\
\hline Overall* & 16 & 2278 & 69.91 & 2 & 243 & 65.41 & 18 & 2521 & 69.48 & 4.85 & $<0.0001$ \\
\hline
\end{tabular}

*Hospitals adopting CPs implemented at least one CP from among the five conditions.

$\mathrm{AMI}$, acute myocardial infarction; CP, clinical pathway.

$\beta$-blockers within 60 hours of admission' for AMI were $77.00 \%, 87.47 \%$ and $64.89 \%$, respectively; the compliance rate for 'Use of $\beta$-blockers only for patients with chronic heart failure' for heart failure was $58.22 \%$; the compliance rate for 'Timeliness of operation (within 2 days of admission)' for C-section was $96.47 \%$; and the compliance rate for 'Severity assessment after admission' for cholecystectomy was $5.78 \%$.

\section{Comparison of compliance rates for different types of hospitals}

Tertiary hospitals had higher compliance rates across the five conditions $(70.95 \%)$ than secondary hospitals $(67.87 \%)$. The differences by hospital level were largest and statistically significant for patients with pneumonia, AMI and cholecystectomy (table 1).

\section{Comparison of compliance rates for hospitals with and without CP implementation}

Hospitals that implemented at least one CP for the five conditions had a higher overall compliance rate $(69.91 \%)$ than those that did not $(65.41 \%)$. The difference in compliance rates between hospitals adopting and those not adopted CPs varied by condition. Specifically, the hospitals that implemented the pneumonia pathway had a much higher compliance rate than those that did not ( $68.27 \%$ vs $58.76 \%, \mathrm{p}<0.0001)$. The hospitals that implemented the cholecystectomy pathway also had a higher compliance rate than those that did not $(69.00 \%$ vs $66.29 \%, p=0.0079$ ) (table 2). The differences for AMI and heart failure were smaller and not statistically significant.

\section{Comparison of the compliance rates of hospitals with and} without financial incentives

Among the hospitals implementing CPs, those that implemented CPs with financial incentives had a higher overall compliance rate than those that implemented CPs without financial incentives $(71.95 \%$ and $65.51 \%, \mathrm{p}<0.0001)$. This relationship existed for patients with four out of five conditions: pneumonia $(69.35 \%$ vs $65.13 \%, \mathrm{p}=0.0235)$, AMI $(71.81 \%$ vs $64.14 \%, \mathrm{p}<0.0001)$, heart failure $(71.56 \%$ vs $64.53 \%, \mathrm{p}<0.0001)$ and $\mathrm{C}$-section $(80.83 \%$ vs $68.08 \%$, $\mathrm{p}<0.0001)$ (table 3).

\section{Factors influencing physician compliance with CPs}

The multivariate linear regression model with hospital fixed effects for patients with five conditions showed that after controlling for other factors, CP compliance rate was lower in patients who had medical insurance $(\mathrm{t}=-5.50, \mathrm{p}<0.0001)$. Compliance rates were higher for

Table 3 Comparison of the average compliance rates of hospitals with or without hospital financial incentives*

\begin{tabular}{|c|c|c|c|c|c|c|c|c|}
\hline \multirow[b]{2}{*}{ Conditions } & \multicolumn{2}{|c|}{ With financial incentives } & \multicolumn{2}{|c|}{$\begin{array}{l}\text { Without financial } \\
\text { incentives }\end{array}$} & \multicolumn{2}{|l|}{ Total } & \multirow[b]{2}{*}{ t Value } & \multirow[b]{2}{*}{$P$ value } \\
\hline & $\begin{array}{l}\text { No of } \\
\text { cases }\end{array}$ & $\begin{array}{l}\text { Compliance } \\
\text { rate (\%) }\end{array}$ & $\begin{array}{l}\text { No of } \\
\text { cases }\end{array}$ & $\begin{array}{l}\text { Compliance } \\
\text { rate (\%) }\end{array}$ & $\begin{array}{l}\text { No of } \\
\text { cases }\end{array}$ & $\begin{array}{l}\text { Compliance } \\
\text { rate (\%) }\end{array}$ & & \\
\hline Pneumonia & 264 & 69.35 & 90 & 65.13 & 354 & 68.27 & 2.29 & 0.0235 \\
\hline AMI & 204 & 71.81 & 112 & 64.14 & 316 & 69.00 & 4.68 & $<0.0001$ \\
\hline Heart failure & 131 & 71.56 & 78 & 64.53 & 209 & 68.94 & 4.13 & $<0.0001$ \\
\hline C-section & 239 & 80.83 & 90 & 68.08 & 329 & 77.34 & 8.21 & $<0.0001$ \\
\hline Cholecystitis & 238 & 66.25 & 30 & 66.67 & 268 & 66.29 & -0.23 & 0.8192 \\
\hline Overall $\dagger$ & 1076 & 71.95 & 400 & 65.51 & 1476 & 70.21 & 8.05 & $<0.0001$ \\
\hline
\end{tabular}

${ }^{*}$ Hospitals that have not adopted clinical pathways were excluded from this table.

†Hospitals adopting clinical pathways implemented at least one clinical pathway from among the five conditions.

AMI, acute myocardial infarction. 
Table 4 Linear regression model for the factors influencing the CP compliance rate*

\begin{tabular}{|c|c|c|c|c|}
\hline Variables & $\beta$ & SE & t Value & $P$ value \\
\hline Intercept & 0.6156 & 0.0195 & 31.51 & $<0.0001$ \\
\hline \multicolumn{5}{|l|}{ Patients' characteristics } \\
\hline Age (years) & -0.0003 & 0.0002 & -1.77 & 0.0764 \\
\hline Medical insurance (1:have, 0:not have) & -0.0393 & 0.0071 & -5.50 & $<0.0001$ \\
\hline AMI (1:yes, 0:no) & 0.0346 & 0.0080 & 4.31 & $<0.0001$ \\
\hline Heart failure (1:yes, 0:no) & 0.0271 & 0.0086 & 3.15 & 0.0017 \\
\hline C-section (1:yes, 0:no) & 0.0973 & 0.0101 & 9.63 & $<0.0001$ \\
\hline Cholecystectomy (1:yes, 0:no) & 0.0185 & 0.0077 & 2.39 & 0.017 \\
\hline Implement the CP of the given condition (1:yes, 0:no) & 0.0057 & 0.0069 & 0.82 & 0.4102 \\
\hline
\end{tabular}

*Hospital fixed effects were used in the model, and the number of cases used in the model was 2479 as statistical analysis system (SAS) default because of missing value in some variables.

$\mathrm{AMI}$, acute myocardial infarction; $\mathrm{CP}$, clinical pathway.

patients for whom the hospitals had implemented financial incentives for compliance for their particular condition $(\mathrm{t}=3.79, \mathrm{p}=0.0002)$; and compliance rates were not associated with the implementation of a $\mathrm{CP}$ in the absence of a financial incentive (table 4).

\section{DISCUSSION}

\section{Moderate implementation of and adherence to CPs}

CPs are viewed as important strategies for improving medical care in China, ${ }^{1}$ but they have not been widely implemented at the hospital level and are not widely adhered to by physicians in Chinese public hospitals. Our study found that the average implementation rate of CPs for five conditions (pneumonia, AMI, heart failure, C-section and cholecystectomy) in 18 surveyed hospitals was $57 \%$ (ranging from $44 \%$ to $67 \%$ ), and the overall average compliance rate for the KPIs for the five conditions was $69.48 \%$ (ranging from $65.07 \%$ to $77.36 \%$ ).

Although average compliance rates in China were moderate for the five conditions, particular KPIs, including Tests and examinations within 3 days of admission for pneumonia and Severity assessment after admission for cholecystectomy, had extremely low physician compliance $(0.75 \%$ and $5.78 \%$, respectively). Because CPs are complex interventions, interprofessional teamwork and organisation/reorganisation of care processes can be problematic in practice. ${ }^{28}$ Poor teamwork and care processes in medical practice may explain low compliance with the timely completion of all tests for and examinations of patients with pneumonia. In addition, poor documentation in the medical records of patients with cholecystectomy may cause low compliance with the KPI of Severity assessment after admission. More studies are needed to explore the specific reasons for these low compliance rates.

\section{Some improvement in CP compliance}

A study of CP compliance rates for patients hospitalised in Shanghai using a similar methodology provides some context for our results. We note that the average compliance rate for patients with AMI reported in this study $(68.87 \%)$ is higher than rates for AMI reported in the Pudong New Area of Shanghai in 2012 (61\%). In particular, the compliance rates for PCI within 90 min of admission $(77.00 \%)$, Thrombolytic therapy within $30 \mathrm{~min}$ of admission (87.47\%) and 'Use of $\beta$-blockers within 24 hours of admission' (64.89\%) were much higher than those reported in the survey of the Pudong New Area $\left(0 \%, 5 \%\right.$ and $25 \%$, respectively). ${ }^{1}$ Because the Pudong New Area is a relatively high socioeconomic status area in Shanghai as well as in China as a whole, it is likely that its compliance with the AMI CP was higher than many hospitals in the rest of the country; thus, we believe these differences over time in compliance rates may reflect improvements over time in medical care for patients with AMI.

Based on this type of reasoning, however, the study did not provide evidence consistent with dramatic improvement in quality of care of patients with other conditions. For pneumonia, heart failure and C-section, the average compliance rates were lower in this study (65.07\%, 68.04\% and $77.36 \%$, respectively) compared with the study of the Pudong New Area $(89 \%, 78 \%$ and $82 \%$, respectively). ${ }^{1}$ In the case of pneumonia, the lower $\mathrm{CP}$ compliance rate may reflect the fact that, in China, it is not easy to follow the CPs for conditions for which 
antibiotic use is the key therapy because overuse of antibiotics is widespread and expected by patients. ${ }^{35-37}$

\section{Organisational and motivational factors influencing compliance with CPs}

Some research suggests that organisational structure, culture, education/orientation/training, administration, capacity of clinical services, medical resources and information systems are the main organisational factors that affect the implementation of and compliance with CPs. ${ }^{322}{ }^{27}$ The fact that tertiary hospitals had a little higher overall compliance rates than secondary hospitals in the study ( $71 \%$ vs $68 \%$ ) may be attributed to their organisational advantages in any or all of the above areas. In addition, the hospitals that implemented at least one of these five CPs had higher compliance rates than those that did not $(69.91 \%$ vs $65.41 \%)$.

An important finding in the study was that the hospitals that implemented CPs with financial incentives had higher compliance with CPs than did those without financial incentives $(71.95 \%$ vs $65.51 \%)$. The linear regression model with hospital fixed effects also found that only when a hospital implemented a CP with financial incentives was compliance higher, suggesting that $\mathrm{CP}$ implementation is more effective when accompanied by financial incentives.

\section{Limitations}

This study only selected five conditions to analyse physician compliance with CPs, although they represent common conditions in internal medicine, surgery and obstetrics. If information was not available in the medical record for a particular indicator, we considered the physician non-compliant. Thus, it is possible that the medical care provided to patients is more compliant with CPs than our results suggest. In addition, the sampling of medical records for use in this study was not fully randomised in some rural areas because electronic health information systems were unavailable. Finally, some factors that may also affect the CP implementation and compliance, such as hospital CP's dissemination strategies, the degree of physicians' trust on guidelines, the level of financial incentives and the number of guidelines implemented in hospitals were not analysed in the study. However, we used hospital fixed effects in multivariate linear regression model to control many other hospital factors that might affect the CP compliance.

\section{CONCLUSIONS}

CPs are viewed as important strategies to improve medical care in China, but they have not been widely implemented or adhered to in Chinese public hospitals. Our study suggests that compliance with CPs is higher when they are implemented in conjunction with physician financial incentives.

Acknowledgements We gratefully acknowledge the significant contributions of Yongcong Chen, Hongbo Zhu, Xuefeng Wei, Minqi Li, Ping Zhou and other students and colleagues in designing this study, gathering information, analysing data and/or sharing their views with us during the research process. The authors also acknowledge all the provincial and area hospitals and Health Commissions that provided assistance with data collection for this research project.

Contributors DX conceived and designed the study. KB, FB and HT designed the study. JB conducted statistical analyses, interpreted the data and drafted and revised the manuscript. KB and DX revised the manuscript. All authors performed the investigation and read and approved the final manuscript.

Funding This research project was supported by the National Natural Science Foundation of China, grant number 71473047, and the CMB-Collaborating Program in Health Technology Assessment, grant number 13-153.

Competing interests JB is a PhD student at the School of Public Health, Fudan University and is a staff member of Pudong Institute for Health Development.

Patient consent for publication Not required.

Ethics approval This study got an approval from the Institutional Review Board (IRB) of the School of Public Health, Fudan University (IRB\# 2014-03-0502).

Provenance and peer review Not commissioned; externally peer reviewed.

Data sharing statement Please contact the corresponding author for data requests.

Open access This is an open access article distributed in accordance with the Creative Commons Attribution Non Commercial (CC BY-NC 4.0) license, which permits others to distribute, remix, adapt, build upon this work non-commercially, and license their derivative works on different terms, provided the original work is properly cited, appropriate credit is given, any changes made indicated, and the use is non-commercial. See: http://creativecommons.org/licenses/by-nc/4.0/.

\section{REFERENCES}

1. He XY, Bundorf MK, Gu JJ, et al. Compliance with clinical pathways for inpatient care in Chinese public hospitals. BMC Health Serv Res 2015;15:1-9.

2. NHC. National Health and Family Planning Commission's notice about implementation of related clinical pathways. $2016 \mathrm{http}: / / \mathrm{www}$. nhfpc.gov.cn/yzygj/s7659/201612/e02b9324fc344f45979b6c20 d7497b71.shtml (accessed 9 May 2017).

3. Gaddis GM, Greenwald P, Huckson S. Toward improved implementation of evidence-based clinical algorithms: clinical practice guidelines, clinical decision rules, and clinical pathways. Acad Emerg Med 2007;14:1015-22.

4. Rotter T, Kinsman L, James E, et al. Clinical pathways: effects on professional practice, patient outcomes, length of stay and hospital costs. Cochrane Database Syst Rev 2010;3:191-2.

5. Böckmann B, Heiden K. PathGuide - model-based generation of guideline-compliant pathways for the use in different hospital information systems. Stud Health Technol Inform 2013;192:1089.

6. Chen YC, Bai J, Wei XF, et al. Analysis on the implementation of clinical pathways in public hospitals in China. Chinese Journal of Hospital Administration 2017;33:21-3.

7. Costa J, Almeida-Brasil CC, Godman B, et al. Implementation of clinical guidelines in Brazil: should academic detailing be used? J Pharm Health Serv Res 2016;7:105-15.

8. Hassaballa H, Payne J, McFolling S, et al. Enhancing clinical pathway placement. Qual Manag Health Care 1998;7:13-17.

9. So JP, Aleem IS, Tsang DS, et al. Increasing compliance with an antibiotic prophylaxis guideline to prevent pediatric surgical site infection: before and after study. Ann Surg 2015;262:403-8.

10. McLeod RS, Aarts MA, Chung F, et al. Development of an enhanced recovery after surgery guideline and implementation strategy based on the knowledge-to-action cycle. Ann Surg 2015;262:1016-25.

11. Egnatios D, Dupree L, Williams C. Performance improvement in practice: managing urinary incontinence in home health patients with the use of an evidence-based guideline. Home Healthc Nurse 2010;28:620-8.

12. Medves J, Godfrey C, Turner C, et al. Systematic review of practice guideline dissemination and implementation strategies for healthcare teams and team-based practice. Int J Evid Based Healthc 2010;8:79-89.

13. Fitzgerald A, Lethaby A, Cikalo M, et al. Review of systematic reviews exploring the implementation/uptake of guidelines. York Health Economics Consortium. 2014 https://www.nice.org.uk/ guidance/ph56/evidence/evidence-review-2-431762366 (accessed 31 Jan 2019).

14. van der Weerd NC, Grooteman MP, Blankestijn PJ, et al. Poor compliance with guidelines on anemia treatment in a cohort of chronic hemodialysis patients. Blood Purif 2012;34:19-27. 
15. Köberlein J, Vent J, Mösges R. On the sustainability of guideline implementation. World Allergy Organ J 2010;3:258-61.

16. Zheng X, Zhong F, Zhang X. Doctors' compliance with national guidelines and clinical pathway on the treatment of tuberculosis inpatients in Hubei, China. J Eval Clin Pract 2014;20:288-93.

17. Biersteker HA, Andriessen TM, Horn J, et al. Factors influencing intracranial pressure monitoring guideline compliance and outcome after severe traumatic brain injury. Crit Care Med 2012;40:1914-22.

18. Adedeji AR, Tumbo J, Govender I. Adherence of doctors to a clinical guideline for hypertension in Bojanala district, North-West Province, South Africa. Afr J Prim Health Care Fam Med 2015;7:776-82.

19. Lalgudi Ganesan S. Costs Associated With "Determinants of Adherence": Essential for Evaluation of Cost-Effectiveness of Any Guideline-Driven Care? Pediatr Crit Care Med 2016;17:901.

20. Nakwatumbah S, Kibuule D, Godman B, et al. Compliance to guidelines for the prescribing of antibiotics in acute infections at Namibia's national referral hospital: a pilot study and the implications. Expert Rev Anti Infect Ther 2017;15:713-21.

21. Hohlfelder B, Kubiak DW, Degrado JR, et al. Implementation of a prolonged infusion guideline for time-dependent antimicrobial agents at a tertiary academic medical center. Am J Ther 2016;23:e176 8-e1773.

22. McConnell T, O'Halloran P, Porter $\mathrm{S}$, et al. Systematic realist review of key factors affecting the successful implementation and sustainability of the Liverpool care pathway for the dying patient. Worldviews Evid Based Nurs 2013;10:218-37.

23. Abrahamson KA, Fox RL, Doebbeling BN. Facilitators and barriers to clinical practice guideline use among nurses. Am J Nurs 2012;112:26-35.

24. Brehaut JC, Hamm R, Majumdar S, et al. Cognitive and social issues in emergency medicine knowledge translation: a research agenda. Acad Emerg Med 2007;14:984-90.

25. Brown SW, Nameth LS. Questions to ask: implementing a system for clinical pathway variance analysis. Outcomes Manag Nurs Pract 1998;2:57-62.

26. Little AB, Whipple TW. Clinical pathway implementation in the acute care hospital setting. J Nurs Care Qual 1996;11:54-61.
27. Ranasinghe I, Rong Y, Du X, et al. System barriers to the evidencebased care of acute coronary syndrome patients in China: qualitative analysis. Circ Cardiovasc Qual Outcomes 2014;7:209-16.

28. Bjurling-Sjöberg $P$, Wadensten $B$, Pöder $U$, et al. Factors affecting the implementation process of clinical pathways: a mixed method study within the context of Swedish intensive care. J Eval Clin Pract 2015;21:255-61.

29. Brusamento S, Legido-Quigley H, Panteli D, et al. Assessing the effectiveness of strategies to implement clinical guidelines for the management of chronic diseases at primary care level in EU Member States: a systematic review. Health Policy 2012;107:168-83.

30. Fernández Urrusuno R, Montero Balosa MC, Pérez Pérez P, et al. Compliance with quality prescribing indicators in terms of their relationship to financial incentives. Eur J Clin Pharmacol 2013;69:1845-53.

31. Doran T, Kontopantelis E, Valderas JM, et al. Effect of financial incentives on incentivised and non-incentivised clinical activities: longitudinal analysis of data from the UK Quality and Outcomes Framework. BMJ 2011;342:d3590.

32. Prior M, Guerin M, Grimmer-Somers K. The effectiveness of clinical guideline implementation strategies--a synthesis of systematic review findings. J Eval Clin Pract 2008;14:888-97.

33. De Allegri M, Schwarzbach M, Loerbroks A, et al. Which factors are important for the successful development and implementation of clinical pathways? A qualitative study. BMJ Qual Saf 2011;20:203-8.

34. Bai J, Bai F, Zhu H, et al. The perceived and objectively measured effects of clinical pathways' implementation on medical care in China. PLoS One 2018;13:e0196776.

35. Ch L, Ah W, Wen X, et al. National health care-associated infection surveillance system point-prevalence trend of antibacterial use in Chinese hospitals 2001-2010. Chin J Nosocomiol 2012;22:4859-61.

36. Li Y, Xu J, Wang F, et al. Overprescribing in China, driven by financial incentives, results in very high use of antibiotics, injections, and corticosteroids. Health Aff 2012;31:1075-82.

37. Heddini A, Cars O, Qiang S, et al. Antibiotic resistance in China--a major future challenge. Lancet 2009;373:30. 